\title{
The Design and Experiments on Integrated Core Curriculum Team(ICCT), for Example, the School of Finance of Hubei University of Economics
}

\author{
Yi Li \\ School of Finance \\ Hubei University of Economics \\ Wuhan City, Hubei Province, China \\ 13476054277@126.com
}

\author{
Zhiwei Xu \\ School of Ethnology and Sociology \\ South-Central University for Nationalities \\ Wuhan City, Hubei Province, China \\ zhiwei-xu@foxmail.com
}

\begin{abstract}
To integrate core curriculum, in-class and out-class learning, and establish new teacher-student relationship, this paper put forward the concept of establishing ICCT. ICCT is much significant to improve teachers' teaching, students' learning, talent cultivation quality, core curriculum system construction, etc. Four parts were designed and experimented, team integration design, core curriculum integration experiment, in-class and out-of-class integration experiment, and teacherstudent interaction integration experiment. ICCT experiment has obtained outstanding achievements, the talent cultivation quality obviously improved and tutorial system fully implemented in our school.
\end{abstract}

Keywords-ICCT; team integration; curriculum integration; in-class and after class integration; teacher-student interaction integration

\section{INTRODUCTION OF ICCT}

In recent years, to strengthen the construction of teachers team, Chinese universities have been taking establishing an enthusiastic and high quality team as a breakthrough, promoting the construction of curriculum system and reform of teaching material.

In abroad, teaching team working is one of the most important ways to improve teaching. In 1950s, American Team Teaching pioneered in teachers collaboration by proposing building up a teaching team. This practice has been achieving big success in the field and positively affecting today's teaching, say the teaching collaboration pattern based on ICE(Integrated Core Experience) in McIntire School of Commerce of University of Virginia. In 1980s, western scholars came up with the concept of Peer Coaching, and advocated teachers value cooperation(partnership formed during working) and co-learning(learning and improving each other's teaching strategy) so that the teaching quality shall be enhanced. According to Wanjin Meng(2004), there were two teaching team cooperation modes that have been largely applied in abroad. One was the whole team mode, a linear organization: establishing team, cooperation design, target and task presentation, team coaching, process presentation, feedbacks and remedies, cooperation guidance, evaluation. The other was core complementary team mode, which determines a core group given on target or the predominant orientation of questions, and the core group was generally made up by one member. Core group required to make plans well in advance, cooperation principles and agenda, etc. With students' continuously in-depth research studies and core group's demands on process of its team coaching, new teachers were absorbed into the group randomly, and team cooperation formed snowballing effect, so that the teachers cooperation team had been expanding continuously.

In China, in the Practicing of University Undergraduate Education Quality and Opinions on Teaching Reform Project in January of 2007, Ministry of Education and Ministry of Finance pointed out: Strengthen undergraduate education team construction. Focus on choosing and establishing a batch of teaching team with high quality and reasonable structure. Establish effective team cooperation organism. Promote the reform and study about teaching material and approaches. Promote teaching seminars and experiences exchanges. Develop teaching resources. Promote the combination of young, middle-aged and old in teaching career. Carry forward the effects of imparting, helping and leading. Strengthen the cultivation of young teachers. Since Ministry of Education suggested establish undergraduate education quality project, educational workers have been doing abundant relative researches, mainly including the concept and characteristics of teaching team, the necessity and significance of establishing teaching team, current situation, problems and policy suggestions on construction of teaching team, etc. The policy suggestions had two main features. One was establishing from face to point, and insisted realizing the construction of teaching team by curriculum construction, teaching material construction, team management and mechanism construction, etc. (eg. Jianfeng Liu and Baolin Wu 2013; Ye Ji and Lin Jiang 2014; Jing Hu and Lirong Bai 2017). The other was paying particular attention to "external force”. For example, Baocun Liu(2007) stated that teaching team construction should be provided with system guarantee via innovation management system, revolution evaluation and assessment mechanism. Jianfeng Liu and Baolin Wu(2013) insisted that teaching team construction should be strengthened by decentralized management, safeguard mechanism and performance appraisal. Jing Hu and Lirong Bai(2017) argued that it had to establish a set of formal and scientific, innovative,

Provincial Teaching Research Project of Hubei Universities( serial number: 2015366) 
realistic rules and regulations for teaching team management. They furthermore pointed out that university should take team as the guide, focus on team performance evaluation, goalmanagement, and evaluation of core team's overall ability and level when setting KPI(key performance indicator), content, assessment methods and evaluation standards, etc.

Resources might be dispersed due to establishment from face to point, and being too dependent on external forces might overlook teachers' subjective initiative, so promoting teaching team construction from point to face or by teachers' internal force could be an effective way. ICCT creates efficient carrier, integrates core curriculum and in-class and after-class study, and establishes new teacher-student relationship through the most important subject of talent development-teachers and students, and the most important part-classroom teaching.

Establishing ICCT could accelerate teachers' transition from "teaching to teaching" to "teaching to learning", and from "giving priority to teaching only within class" to "inclass and after-class combination"; students' transition from "passive learning" to "active learning", and from "common learning” to "personalized learning”, which is helpful to improve the quality of talent cultivation; get the teaching reform practice "tutorial system, small class, personalization, and internationalization" integrated, so that it could spare an effective path for further deepening university's reforms of pilot colleges; provide with helpful references for the practice of core curriculum system in the Talent Cultivation Scheme, so the very position of core curriculum teaching be reflected in talent cultivation; and provide talent cultivation of small classes with effective samples, which has demonstration significance to universities' talent cultivation reform modes.

\section{DESIGN AND EXPERIMENTS}

\section{A. The Design of Team Integration of ICCT}

To respect students' personalized development and fully inspire teachers' enthusiasm and creativity, Finance School of Hubei University of Economics has been devoted to establish professional core curriculum team based on major(or class) core curriculum. So far, core curriculum teams for two majors have been established, one for finance major, and the other for insurance major. In the meantime, Ten Opinions of Finance College of Hubei University of Economics on Supporting Major Core Curriculum Construction was published. For instance, it supported teachers' transition from "teaching to teaching” to “teaching to learning”, and students' transition from "passive learning” to "active learning”, making full use of initiative of teachers and students, reforming class teaching approaches; encouraged team to integrate curriculum content, realize the totalization of curriculum, implement major core curriculum system; and establishing team beyond colleges, majors and curriculums was welcomed; gave team priority support to implement practice and training relying on major(or class) in a systematic way; Furthermore, team members received strong support as priority on autonomy of teaching management, educational expenditure, teachers' further education, and other aspects. These measures are beneficial to form such operation mechanism, independent teaching and learning.

\section{B. Experiment on Core Curriculum Integration of ICCT}

Since teachers who teach different curriculums lack interaction mechanism, especially for teachers that teach different majors, which makes curriculum teaching is fiercely independent among them, and logic of curriculum system is impacted by fragmented curriculums in real practice, so it is necessary to realize the systematization of curriculum via integrated core curriculum teaching. This experiment was on the basis of core curriculums in talent cultivation scheme and through strengthening the communication within disciplines and the mixture among different disciplines, re-establishing traditional curriculums and making new design on modular curriculums to achieve the totalization of curriculums according to "three increases and three decreases" principle(increasing comprehensive curriculums and decreasing single ones, increasing frontier curriculums and decreasing outdated ones, and increasing the ratio of optional courses and decreasing the compulsory courses'). At present, our curriculum system is made up of six parts, general compulsory courses, general optional courses, specialized elementary courses, major compulsory courses, major optional courses, and practicing and experimenting courses. To effectively improve the teaching quality of major core curriculums and overcome disadvantages of traditional assessment methods, the new assessment system emphasizes process evaluation and assessment, and the flexibility of assessment methods, what's more, it gets rid of the traditional instilling teaching mode and forms advanced teaching concepts step by step, such as heuristic teaching, open teaching, online teaching, and individualized teaching, etc.

\section{Experiment on In-class and After-class Integration of ICCT}

ICCT experiment fully respected students' own choices, enlarged students' autonomy, emphasized teaching and examination reforms, encouraged students to have second classes, and supported students engaging in projects, key base, and team as soon as they could. Promoting students' personalized developments through key parts, such as selecting courses, teaching, and assessment, etc., in and after classes, in and out of university. In regards to autonomy option, initially, we implemented flexible educational system in top finance innovation class. The traditional credit-based system was replaced by 3 to 6years' flexible educational system, and students could graduate when they finished the stipulated scores within 3 to 6 years' study in school. Secondly, abundant curriculum modules were designed. By making use of the professional foundation knowledge platform based on comprehensive major compulsory courses, we opened abundant major optional classes to help realize the talent cultivation goal-talent engineering. Selecting courses across colleges and majors was available for students not only from initial top finance innovation class, but also all students of our school. In the meantime, 4 to 5 weeks' small semester during summer vacation was designed for one to three years' students, developing oversea study and professional practice and experiment and other teaching activities. Batches of students had been organized to experience oversea study during 2013 and 2016. Regarding teaching, we attempted to arrange several teachers for one curriculum, 6 professors co-taught 
International Finance, and 4 co-taught Risk Management and Insurance. We respected students as class-teaching players, encouraged teachers to adopt heuristic, explorative, participatory, situational, and case teaching methods, creating the academic atmosphere of students' active learning.

In addition, to further improve the quality of undergraduate curriculum teaching and promote active learning, our school implemented undergraduate teaching assistant system. It contained two types, class assistant and curriculum assistant. Class assistant Played an important role in answering students' questions from out-of-class learning, homework feedbacks, and exchanges of learning experiences, while curriculum assistant made great contributions to attending course lectures, recording student attendance, understanding teaching progress and students' learning situation, tutoring students having discussion classes(or exercise classes), and answering students' questions from out-of-class learning. There have been no less than 10 undergraduate class assistants, and no less than 8 undergraduate and four graduate curriculum assistants for every semester since 2015.

Speaking of the coordination between curricular and extracurricular knowledge, to reinforce students' in-depth understanding and real application of curriculums, we have respectively organized students from two to four classes to have practical skills training in Bank of Communications, Hubei Branch, Agricultural Bank, Hubei Branch, Taikang Life Insurance, Wuhan Backup Center, Chang An Property \& Liability Insurance, Hubei Branch, People’s Government of Xishui County, etc.

We offered strong support on students early engaging in research activities, projects, key base, and team. 61 students participated in the study and research of 8 national research groups, and students made outstanding achievements in many scientific researches and contests.

In-class and out-of-class integration get class teaching and second class integrated, and theoretical study and practical teaching organically combined, promoting students' active learning and personalized development.

\section{Experiment on Teacher-student Interaction Integration of ICCT}

Experiment on teacher-student interaction integration of ICCT established many-to-many undergraduate tutorial system, with students' active involvements and teachers' organic cooperation. Tutorial system is significant to improve the development of university, the quality of talent cultivation and teachers, which has been taken seriously by universities. Finance College of Hubei University of Economics is definitely one of them, exploring establishment from point to face and implementing tutorial system. In March of 2011, to further execute the "internationalization, engineering, totalization and personalization" talent cultivation targets of schemes on cultivating top finance innovation talents, our college implemented binary tutor system test plans for top finance innovation talent cultivation, academic tutorial system, and industry tutorial system. Academic tutorial system was for freshman, sophomore, and junior year. Academic tutor was with strong openness and good science base. Tutors came from four core curriculums of College of Applied Economics, and the ratio of tutors outside the department was $40 \%$, which evidenced its openness; Tutors who takes charges of projects supported by National Social Science Foundation and humanities and social science project supported by Ministry of Education accounted for $60 \%$ among 20 tutors in first batch, which reflected its good research base. The primary liabilities of academic tutor were communicating with students regularly, helping them establish a correct outlook on life and values, determining learning targets and plans, making and implanting personalized learning programs to develop students' professional thinking and foundations. Industry tutorial system was implemented during junior and senior years. Industry tutors were made up by social good education resources, alumni, and elites from financial sector, etc., introducing latest industry developments, sharing personal experiences, leading students to practice social activities as per their real interests, and improving their innovation and entrepreneurial ability, and employability by lectures, reports, and co-teaching, etc.

In September of 2013, we implemented undergraduate tutorial group, advocating that tutors and students increase contact area and deepen tightness. Building up new teacherstudent relationship could lead students to establish a correct outlook on life and values, assist them to make realistic learning schemes for themselves, and guide their study.

In October of 2016, on the basis of summarizing above tutorial system experiences, we published Undergraduate Tutorial System Working Methods for College of Finance of Hubei University of Economics, and fully implemented undergraduate tutorial system. Tutors could guide students by face-to-face guidance, special topic lectures, academic reports, organizing discussions, participating in research projects, also including phones, e-mails, "network communication platform", in-school and out-of-school visits, social practices, professional practices and various approaches. Tutors were encouraged to combine tutoring work and curriculum assistants and student research assistants.

\section{ACHIEVEMENTS}

\section{A. Obvious Improvement of Quality and Outstanding Effects of Talent Cultivation}

Through recent years' experiments, our college's quality of talent cultivation has been improved obviously and obtained outstanding Effects.

Employment rate, graduation rate, overseas further study rate of four-year undergraduate curriculum have increased respectively from $84.78 \%, 20.9 \%$ and $5.97 \%$ of 2013 to $92.2 \%$, $24.23 \%$ and $8.42 \%$ of 2016. We won 4 and 7 China Ping An Inspirational Plans Paper Awards(undergraduate finance team) respectively in 2015 and 2016, ranking top1 among national universities, and earned high praises from jury made up by national notable finance scholars. And received 5 first and second Hubei University undergraduate outstanding research achievements prizes of 2016 in total. The prizes levels and numbers ranks third place among tier 2 universities of Hubei.

And quality indicators of talent cultivation of four-year finance major have been largely increased too. In 2016, employment rate, graduation rate, and oversea further study 
rate increased respectively from $81.9 \%, 23.53 \%$, and $6.79 \%$ of 2013 to $96.32 \%, 29.77 \%$ and $12.37 \%$; the awards of contests above the provincial level and numbers of published papers increased respectively from 14 to 36 and 6 to 27 .

The first two graduates in top innovation class have obtained 22 awards of provincial level contests and above that , graduation rate was $40.74 \%$ and $64.29 \%$, overseas further study rate was $22.22 \%$ and $46.43 \%$; Numbers of China Ping An Inspirational Plans Paper Awards(undergraduate finance team) ranked top1 among finance major students in national universities.

Employment rate in Agricultural Bank Chang Jiang Class was $100 \%$, 38 students had campus recruitment on-site tests organized by China Agricultural Bank, and created the best record of highest passing rate-90\% among national single classes.

\section{B. Implementation of Fully Tutorial System}

Fully tutorial system has been implemented in our college. To improve students cultivation effects, we attempted various approaches, tutor group regularly tutoring, academic tutor arrangements, and industrial tutor teaching, etc. Summarizing experiments on above tutorial system, Undergraduate Tutorial System Working Methods for College of Finance of Hubei University of Economics was published, and undergraduate tutorial system has been fully implemented, which is beneficial to the interaction between teacher and student and promote students' own quality comprehensive development.

\section{CONCLUSION}

The construction of ICCT promotes the concept transition of teachers teaching and students learning, teachers' transition from "teaching to teaching" to "teaching to learning", and "giving priority to teaching only within class" to "combination of in and after class", students' transition from "passive learning" to "active learning", and "common learning” to "personalized learning”. The School of Finance of Hubei University of Economics established core curriculum teams for finance innovative talent cultivation and insurance talent cultivation, published matched supportive policies, integrated core curriculum to realize the totalization of curriculums, and innovated in the assessment approaches and teaching methods of integrated core curriculum. Also, we paid great importance to second classes' learning, so that theoretical study could combine with real practice mechanically, which promotes student's active learning and personalized development. What's more, tutorial system was fully implemented to strengthen teacher-student interaction and promote students' development.

\section{REFERENCES}

[1] Wanjin Meng, Collaboration and Mutual Help-the Education Power of Resources Integration, Shanghai East China Normal University Press, 2004, pp. 98-99.(In Chinese)

[2] Baocun Liu, "Establishing high quality teaching team, and promoting the improvement of undergraduate teaching quality." Chinese High Education, 2007, (05): 29-31. (In Chinese)

[3] Jianfeng Liu, and Lin Jiang, "The construction and management analysis on university teaching team.” Chinese University Teaching, 2013, (04): 80-82. (In Chinese)

[4] Ye Ji, and Lin Jiang, "The study of construction of university outstanding teaching team.” Beijing High Education, 2014,(04): 70-71. (In Chinese)

[5] Jing Hu, and Lirong Bai, "Discussions on the construction of local undergraduate university teaching team.” Hengshui College Paper, 2017(In Chinese)

[6] Qiang Qiu “Analysis of strategy of teachers' teaching ability improvement under duple influence of team construction and universityenterprise cooperation.” Education Review, 2015,4(21):65-66. (In Chinese) 